\title{
NOVEL APPLICATION OF TRICHILIA HEUDELOTII PLANCH: EFFECTIVENESS OF DIFFERENT POLARITY OF ORGANIC SOLVENTS OF LEAF AND STEM BARK EXTRACTS ON THE CONTROL OF COWPEA BEETLE
}

\author{
R.O. UDDIN II ${ }^{1, *}$, G.V. AWOLOLA ${ }^{2}$, S. MUSTAPHA ${ }^{1, *}$, O.H. ABDULAZEEZ ${ }^{1}$, \\ O.T. ILESANMI ${ }^{1}$, S.A. ALIYU ${ }^{3}$ \\ *E-mail: juniorsuleiman78@gmail.com
}

Received: June 10, 2020. Revised: July 24, 2020. Accepted: Aug. 10, 2020. Published online: Oct. 16, 2020

\begin{abstract}
Callosobruchus maculatus (cowpea beetle) is a field-to-store pest causing over $90 \%$ losses of cowpea. The search for new plant-derived crop protectant that can be explored as alternative to synthetic pesticides is urgently needed. Thus, the phytochemical screening, as well as the bioactivity of different polarity of organic solvents of leaf and stembark extracts of Trichilia heudelotii (Meliaceae), was investigated against the field-to-store insect pest Callosobruchus maculatus in laboratory bioassay. The non-polar (hexane) and polar (ethanol) extracts [0.0 (control), 0.5, 1.0 and $1.5 \mathrm{ml}$ ] of the leaf and stem bark were added to $100 \mathrm{~g}$ of cowpea. The following parameters of the cowpea weevil life cycle were analysed at the
\end{abstract}

various concentrations: adult mortality, oviposition rate, number of larvae and pupae, and emergence of first filial progeny. The phytochemical screening revealed the presence of flavonoids, terpenoids, alkaloids, saponins in both the non-polar and polar extracts. Furthermore, the various treatments used were significantly $(p<0.05)$ effective in controlling $C$. maculatus from 1 and also 30 days after treatment (DAT) for both the non-polar and polar extracts when compared to the control. However, the most effective treatment was observed with the polar (EtOH) stem bark extract at $1.5 \mathrm{ml}$, which caused more mortalities and fewer emergence of the insect. Our findings suggest that the non-polar and polar leaf and stem bark of $T$. heudelotii

\footnotetext{
${ }^{1}$ Department of Crop Protection, University of Ilorin, Ilorin, Nigeria

2 Department of Industrial Chemistry, University of Ilorin, Ilorin, Nigeria

${ }^{3}$ Department of Crop Protection, Ahmadu Bellow University, Zaria, Nigeria
} 
extracts could serve as a sustainable and potential alternative to synthetic chemicals in pest control.

Keywords: Callosobruchus maculatus; Trichilia heudelotii extracts; bio-pesticide; insect pest control.

\section{INTRODUCTION}

$\begin{array}{cccc}\text { The crop cowpea (Vigna } & \text { cols } \\ \text { unguiculata } & \text { (L.) Walp.) is an }\end{array}$ important food and forage legume grown in the semi-arid tropics, which include parts of Asia, Africa, Southern United States, Central and South America and Southern Europe (Singh, 2005; Timko et al., 2007a). It is a multifunctional crop, providing nutrition for both man and livestock and serving as a dependable and liable revenue-generating commodity for traders and farmers (Singh, 2002; Langyintuo et al., 2003). The crop is attacked by many pests, which includes the cowpea weevil Callosobruchus maculatus.

The bruchid beetle, Callosobruchus maculatus (Fabricus) of the Chrysomelidae family, is a reddish-brown insect with black and gray elytra, marked with two central black spots (Fox and Reed, 2011). They are usually sexually dimorphic and the sexes are easily distinguished from each other. Females are sometimes larger and darker than males (Beck and Blumer, 2014) and they exists in two morphs; the flightless and the flying form. The flying form is more common in beetles that developed in conditions of high temperature like the tropics (Umar and Turaki, 2014). A female
C. maculatus has been reported to lay more than a hundred eggs on the surface of cowpea with most of the eggs viable and hatching. Larvae of the insect emerges after four to eight days and then burrow themselves into the seeds (Umar and Turaki, 2014). The larva proceeds to feed on the seed content usually feeding on the embryo and then leaving tiny holes through, which it will exit when it matures to adult after three to seven weeks depending on the environmental situations. The higher the temperature the quicker the rate of development. The adult period ranges from 9-14 days (Beck and Blummer, 2014).

Callosobruchus maculatus is a field-to-store insect pest. Infestation begins from the field and damage continues in storage (Ali et al., 2004; Swella and Mushobozy, 2007). Estimates of storage losses have been reported from 4 - $90 \%$ due to punctures caused by the beetles, thus reducing the degree of usefulness and rendering seeds unfit for planting or consumption (Ali et al., 2004; Umeozor, 2005). Kéïta et al. (2000) also reported that $C$. maculatus can cause weight loss by up to $60 \%$ when cowpea seeds are stored without any protection.

Plants are known to have evolved millions of years ago to defend themselves from external attacks by pests, in so doing, they develop natural repellent mechanisms that are antagonistic to a varying degree of pests. In addition, as a result of the problems associated with pesticide resistance, negative effects 
on non-target organisms, man and the environment, the idea of using plant materials as natural (botanical) insecticides to protect crops from damages incurred by insect pest is a safer alternative in pest control, when compared to the hazardous effects of synthetic chemicals and this is gaining much prominence among researchers and household users (Lajide et al., 2003). From ancient times, these plant materials have been noticed and used as natural insecticides in stored grains by mixing grains with leaf, bark, seed powder or oil extracts of plants to suppress insect infestation and developments in grains (Addor, 1995; Talukder et al., 1995). Thus, these botanical insecticides are naturally occurring biochemicals that are broken down easily and readily unlike synthetic chemical pesticides (Egho, 2011).

In this study, Trichilia heudelotii (Meliaceae) leaves and stem bark were used against the bruchid beetle Callosobruchus maculatus. The plant has gained the attention of many phytochemists interested in bioproduction due to its diverse classes of compounds identified as well as insecticidal actions against several insect pests (Vieira et al., 2013; Bankole et al., 2016). Over the years, phytochemical investigation had revealed that the genus Trichilia is rich in various classes of compounds, which includes terpenoids, steroids, flavonoids and other terpenes by-products (Ramirez et al., 2000; Rodrigues et al., 2010; Vieira et al., 2014). Furthermore, a wide range of research had been reported on various extracts of the different species from the genus Trichilia revealing insecticidal activities on different groups of insect pests (Xie et al., 1994; Ayo et al., 2013; Freitas et al., 2014). Previously, there has been various reports of other species of the genus Trichilia used in the control of various insect pests (López-Oleguín, 1998; Isman, 2001; Sengottayan, 2013; Curcino-Vieira et al., 2014; Garcia-Gomez et al., 2019); however the species Trichilia heudelotii is yet to be evaluated for its insecticidal potential. Thus, this prompted us to investigate the effectiveness of Trichilia heudelotii leaf and stem bark non-polar and polar extracts as natural insecticides in the control of Callosobruchus maculatus infesting cowpea, which to the best of our knowledge has not been studied previously and to carryout phytochemical screening on the extracts.

\section{MATERIALS AND METHODS}

\section{Sample collection and identification}

Fresh leaves and stem bark of Trichilia heudelotii were collected from a thick forest in Oyan town, Osun State, Nigeria. The plant was authenticated at the Ward Herbarium of the University of Ilorin, and was assigned a voucher number, UILH/001/1367.

\section{Sample preparation and Extraction}

The Trichilia heudelotii leaves and stem bark were air-dried at room temperature. The dried leaves and stem bark were ground using an electric grinder 


\section{NOVEL APPLICATION OF TRICHILIA HEUDELOTII ON THE CONTROL OF COWPEA BEETLE}

and sieved using a 90-micron mesh sieve to obtain fine powder of the samples.

The powdered leaves (650 g) and stem bark $(1.1 \mathrm{~kg})$ were extracted twice by maceration, sequentially with a nonpolar and polar organic solvents, hexane (Hex) and ethanol (EtOH), respectively. Yields of $14.26 \mathrm{~g}$ (Hex) and $10.24 \mathrm{~g}$ $(\mathrm{EtOH})$ of the leaves was obtained after evaporation of the organic solvents. For the stem bark, 9.26g (Hex) and $13.59 \mathrm{~g}$ $(\mathrm{EtOH})$ was obtained.

The crude extracts obtained used for the experiment were then prepared using an aqueous solution of $1 \% \mathrm{v} / \mathrm{v}$ of acetic acid in distilled water and concentrated at $0.5 \mathrm{~g}$ per $\mathrm{ml}$.

\section{Qualitative phytochemical screening}

Test for tannins. Few drops of $1 \%$ lead acetate was added to $0.2 \mathrm{~g}$ of the extract and observed for the formation of yellow precipitate (Trease and Evans, 1989).

Test for alkaloids. Exactly $0.2 \mathrm{~g}$ of the extract was stirred with $5 \mathrm{ml}$ of $1 \%$ aqueous $\mathrm{HCl}$ on water bath and then filtered. One $\mathrm{ml}$ of the filtrate was taken individually into two separate test tubes. To the first portion, Mayer's reagent was added and appearance of buff-colored precipitate was an indication for the presence of alkaloids. To the second portion, few drops of Dragendorff's reagent was added to the filtrate and observed for the formation of an orangered precipitate (Sofowora, 1993).

Test for terpenoids (Salkowski test). Exactly $2 \mathrm{ml}$ of chloroform was added to $0.2 \mathrm{~g}$ of the extract, $3 \mathrm{ml}$ of concentrated sulphuric acid was added carefully to form a layer. Formation of a reddishbrown colouration at the interface indicates the presence of terpenoids (Sofowora, 1993).

Test for phenolic compounds. The extract $(0.5 \mathrm{~g})$ was dissolved in $5 \mathrm{ml}$ of distilled water. To this, few drops of neutral 5\% ferric chloride solution was added. A dark green colour indicates the presence of phenolic compounds (Sofowora, 1993).

Test for flavonoids. Exactly $4 \mathrm{ml}$ of dilute ammonia solution was added to a portion of the extract, followed by addition of concentrated sulphuric acid. A yellow colouration indicates the presence of flavonoids (Sofowora, 1993).

Test for saponins. Exactly $1 \mathrm{~g}$ of the extract was boiled with $5 \mathrm{ml}$ of distilled water and filtered. To the filtrate, about $3 \mathrm{ml}$ of distilled water was further added and shaken vigorously for about $5 \mathrm{~min}$. Frothing which persists on warming shows the presence of saponins (Trease and Evans, 1989).

Test for anthraquinones. Few drops of dilute sulphuric acid were added to $0.2 \mathrm{~g}$ of the extract. This was boiled and filtered. The filtrate was extracted with $2 \mathrm{ml}$ of chloroform. The chloroform layer was then treated with $1 \mathrm{ml}$ of ammonia. The formation of red colour on the ammoniacal layer shows the presence of anthraquinones (Sofowora, 1993; Harborne, 1973).

Test for steroids. Acetic anhydride ( $2 \mathrm{ml}$ ) was added to a portion of the extract with $2 \mathrm{ml} \mathrm{H}_{2} \mathrm{SO}_{4}$. Colour change from violet to blue or green indicates the presence of steroids (Sofowora, 1993).

Test for anthocyanins. Exactly $3 \mathrm{ml}$ of $2 \mathrm{M} \mathrm{HCl}$ and ammonia solution were added to a portion of the extract. The appearance of pink-red colouration which turns blue-violet indicates the presence of anthocyanins (Savithramma et al., 2011).

\section{Insect culture}

The method of Ousman et al. (2007) was adopted in rearing of $C$. maculatus. The insects were obtained from an existing culture from Nigerian Stored Products Research Institute (NSPRI), Ilorin, 
Nigeria. Eight pairs of active male and female $C$. maculatus were introduced into transparent plastic containers $(7 \times 8 \mathrm{~cm})$ containing untreated cowpea seeds. Next, they were allowed to mate and oviposit for seven days. The plastic containers were covered with muslin cloth held in place by a rubber band to prevent escape of the insect and allow for ventilation. After one week, the introduced $C$. maculatus were removed and the containers were left under laboratory conditions (temperature $24^{\circ}-28^{\circ} \mathrm{C}$, relative humidity of $70 \%$ ) till the emergence of $F_{1}$ progeny. The $F_{1}$ progenies from the cultures were used for the experiment.

\section{Source and type of cowpea seeds used}

The cowpea variety IT96D-610 was obtained from the International Institute for Tropical Agriculture (IITA), Ibadan, Nigeria. The variety is characterized by having a smooth seed coat, high root biomass and also drought-resistant. Clean and undamaged seeds were picked and used for the experiment. The cowpea seeds were stored in the freezer compartment of a refrigerator at $-17^{\circ} \mathrm{C}$ for four days to incapacitate any existing insects before experimenting.

\section{Experimental procedure and design}

$100 \mathrm{~g}$ of clean and undamaged cowpea seeds were placed in transparent plastic containers $(7 \times 8 \mathrm{~cm})$. The seeds were properly mixed with the various levels of the botanical extracts $(0.5 \mathrm{ml}$, $1.0 \mathrm{ml}$, and $1.5 \mathrm{ml}$ ) of each treatment using a wooden spatula to ensure uniform coating of the seeds. The seeds were airdried for $5 \mathrm{~min}$. before introducing four pairs of active male and female C. maculatus (24 hrs old) into the treatments. The containers were covered with muslin cloth tied with rubber band to allow for ventilation and prevent escape of C. maculatus.
The experiment was arranged in a Completely Randomized Design (CRD) with five treatments (hex leaf; hex stem bark extracts [non-polar extract] and EtOH leaf; EtOH bark extracts [polar extract $]$ and control $)$ at three levels $(0.5 \mathrm{ml}$, $1.0 \mathrm{ml}$ and $1.5 \mathrm{ml}$ ) and each level was replicated three times plus the control. The experiment was carried out in two batches, which was dependent on the period of introduction of $C$. maculatus into the experimental units. Introduction of C. maculatus into the experimental units was done immediately after seed treatment for the first batch, while the second batch was infested 30 days after seed treatment to test for the strength of shelf life of the plant extracts. All the experimental units were treated at the same time. The experiment was carried out under ambient laboratory conditions.

\section{Data collection}

Data were collected on the following parameters:

Adult mortality. This was taken for five consecutive days. The insects were confirmed dead when there was no response to probing with an entomological needle at the abdomen, leg or antennae. The numbers of dead C. maculatus were counted daily and recorded.

Oviposition rate. This was taken at seven days after infestation. Ten seeds were randomly selected and seeds were viewed for the presence of eggs using $\mathrm{a} \times 100$ magnifying lens.

Number of larvae and pupae. For the presence of larvae and pupae, four seeds were selected at random and seeds were carefully dissected using a sharp surgical knife to expose larvae and pupae in seeds. The numbers of larvae were taken 13 days after treatment while the number of pupae was recorded 18 days after treatment. 
Emergence of $F_{1}$ progeny. At 28 days after treatment, observation was taken for the emergence of new progeny of the weevil by counting newly emerged adults found in each of the treatments.

\section{Statistical analysis}

Data were subjected to two-way analysis of variance (ANOVA). Where treatment means were significant, multiple comparisons of treatments was done using the new Duncan's Multiple Range Test (n DMRT) at 5\% level of significance. All statistical analysis was done using statistical package of social science (SPSS) version 20.

\section{RESULTS}

Effect of Trichilia heudelotii extracts on adult mortality of Callosobruchus maculatus after treatment

Tables 1 and 2 show the effects of the different extracts (non-polar and polar) of Trichilia heudelotii on the mortality of adults of $C$. maculatus from 1 and 31 days after treatment (DAT). Post hoc analysis revealed that there were significant differences between the treatment of the extracts of $T$. heudelotii and the control at 1 and 2 DAT (Table 1). The polar EtOH extract (Table 1) of T. heudelotii stem bark had a significantly $(p<0.05)$ higher rate of adult mortality of C. maculatus at the concentrations of $1.5(\mathrm{M}=7.00 \pm 1.00)$ and $1.0 \mathrm{ml}(\mathrm{M}=$ $6.33 \pm 1.528$ ), respectively, at 1 DAT. It was also observed that at $1 \mathrm{DAT}$, all the treatment extracts of $T$. heudelotii were effective in significantly $(p<0.05)$ increasing the number of adult mortality, when compared to the control, which only had a mortality rate of $2.33( \pm 0.577)$ (Table 1). At 2 DAT, the EtOH leaf extract (polar extract) was significantly $(p<0.05)$ the highest in causing more adult mortality of C. maculatus at $1.0 \mathrm{ml}$ $(\mathrm{M}=5.33 \pm 0.577)$, when compared to the other extracts and the control (Table 1).

In addition, observations on the shelf life of the treatments revealed that the EtOH stem bark (polar) extract of $T$. heudelotii at the concentration rate of $1.5 \mathrm{ml}$ was significantly $(p<0.05)$ able to suppress the population of $C$. maculatus adults $(\mathrm{M}=7.00)$, followed by $1.0 \mathrm{ml}$ $(\mathrm{M}=6.33)$ and $0.5 \mathrm{ml}(\mathrm{M}=6.00)$, i.e. in a dose dependent manner, respectively, when compared to the other treatment extracts, which were lower at 31 DAT, as shown in Table 2.

\section{Effect of Trichilia heudelotii extracts on oviposition rate of Callosobruchus maculatus 7 and 37 days after treatment}

The effects of the extracts at varying concentrations of $T$. heudelotii on the oviposition rate of $C$. maculatus from 7 and 37 days after treatment (DAT) is shown in Table 3. There were significant differences between the non-polar and polar leaf and stem bark extracts and the control.

All the extracts were significantly able to control the oviposition rate of $C$. maculatus at 7 and 37 DAT however, the EtOH stem bark (polar) extract had the lowest mean number of oviposition ( $\mathrm{M}=1.33)$ at the concentration rate of $1.5 \mathrm{ml}$, 
which was significantly $(p<0.5)$ able to suppress the oviposition rate of C. maculatus. This was also observed at $37 \mathrm{DAT}$, showing the least mean number (2.00) of oviposition, when compared to the control (Table 3). During the cause of the experiment, the control did not affect the rate of oviposition of C. maculatus.

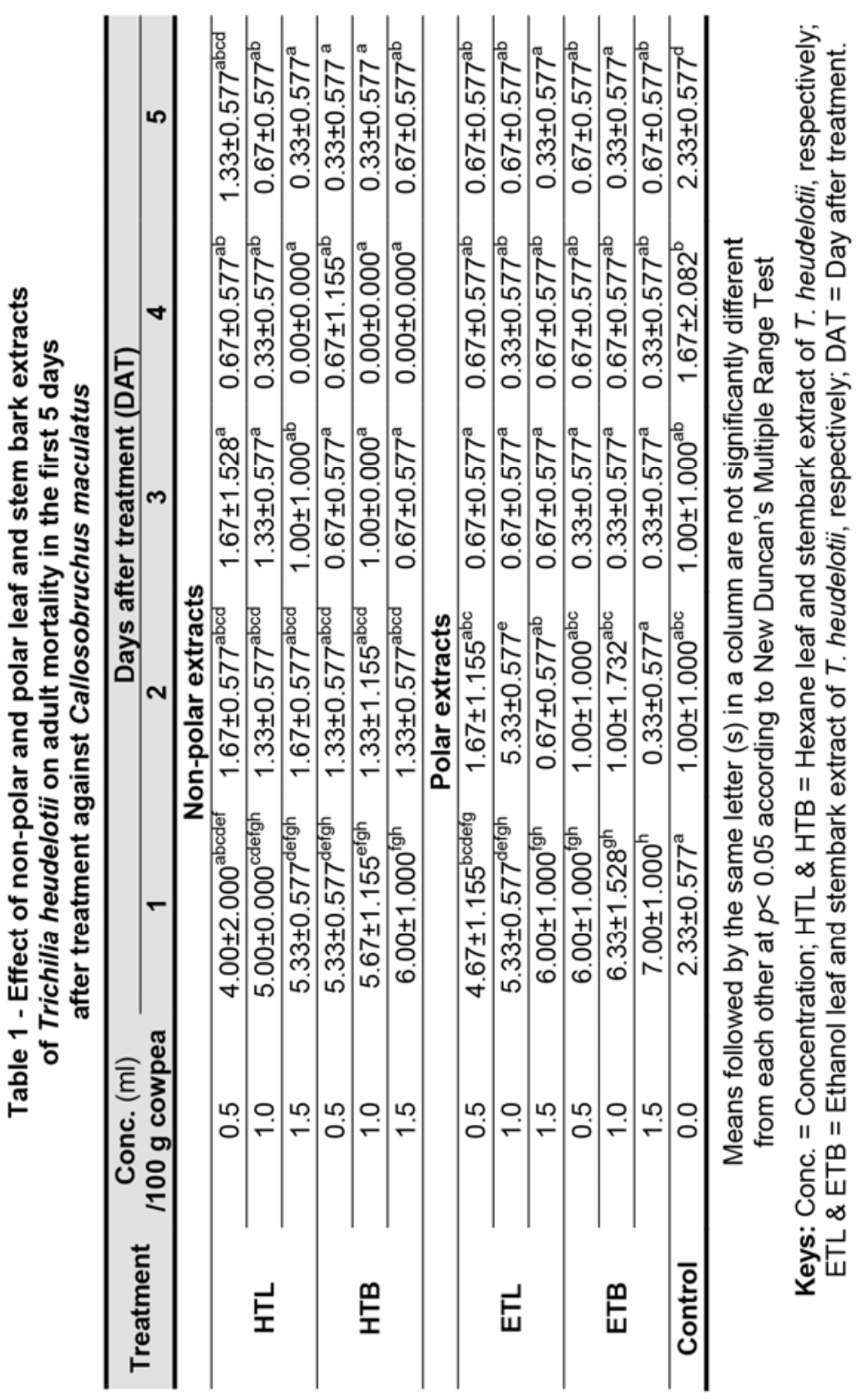




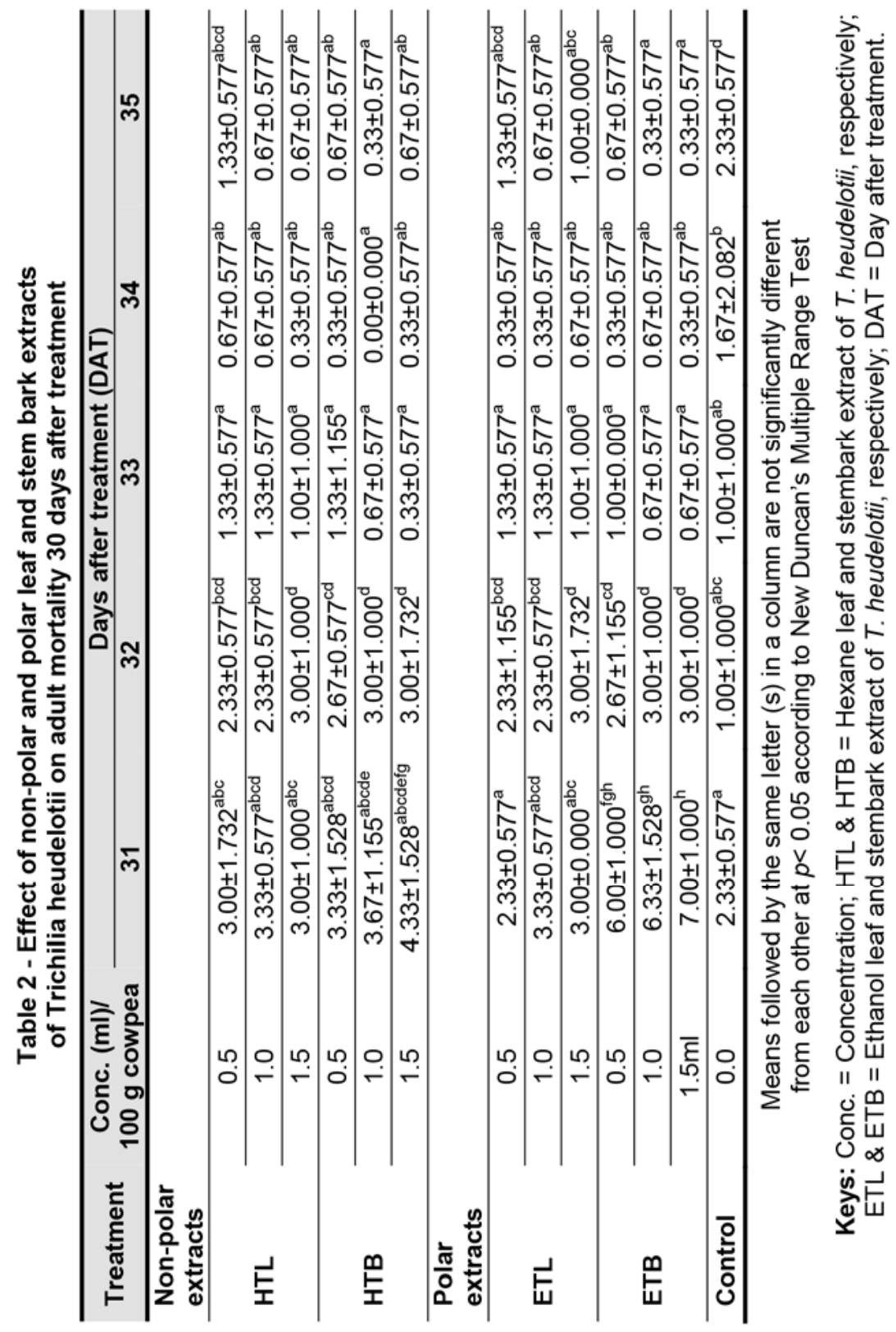


Table 3 - Effect of non-polar and polar leaf and stem bark extracts of Trichilia heudelotii on oviposition rate

\begin{tabular}{|c|c|c|c|}
\hline \multirow{2}{*}{ Treatment } & \multirow{2}{*}{ Conc. $(\mathrm{ml}) / 100 \mathrm{~g}$ cowpea } & \multicolumn{2}{|c|}{ Days after treatment (DAT) } \\
\hline & & 7 & 37 \\
\hline \multicolumn{4}{|c|}{ Non-polar extracts } \\
\hline \multirow{3}{*}{ HTL } & 0.5 & $4.00 \pm 2.00^{\text {bcde }}$ & $4.33 \pm 1.528^{\mathrm{cde}}$ \\
\hline & 1.0 & $3.00 \pm 2.646^{\text {abcde }}$ & $4.00 \pm 1.000^{\text {bcde }}$ \\
\hline & 1.5 & $3.33 \pm 1.528^{\text {abcde }}$ & $3.33 \pm 1.155^{\text {abcde }}$ \\
\hline \multirow{3}{*}{ HTB } & 0.5 & $2.33 \pm 0.577^{\text {abcd }}$ & $2.67 \pm 0.577^{\text {abcde }}$ \\
\hline & 1.0 & $1.67 \pm 0.577^{\mathrm{ab}}$ & $2.33 \pm 0.577^{\mathrm{abcd}}$ \\
\hline & 1.5 & $2.33 \pm 0.577^{\text {abcd }}$ & $2.67 \pm 0.577^{\text {abcde }}$ \\
\hline \multicolumn{4}{|c|}{ Polar extracts } \\
\hline \multirow{3}{*}{ ETL } & 0.5 & $4.00 \pm 1.000^{\text {bcde }}$ & $4.33 \pm 1.155^{\mathrm{cde}}$ \\
\hline & 1.0 & $3.33 \pm 1.000^{\mathrm{bcde}}$ & $3.33 \pm 0.577^{\text {abcde }}$ \\
\hline & 1.5 & $3.00 \pm 1.000^{\text {abcde }}$ & $3.00 \pm 1.000^{\text {abcde }}$ \\
\hline \multirow{3}{*}{ ETB } & 0.5 & $2.33 \pm 0.577^{\mathrm{abcd}}$ & $2.67 \pm 0.577^{\text {abcde }}$ \\
\hline & 1.0 & $1.67 \pm 1.155^{\mathrm{ab}}$ & $2.67 \pm 1.155^{\text {abcde }}$ \\
\hline & 1.5 & $1.33 \pm 0.577^{\mathrm{a}}$ & $2.00 \pm 0.000^{\mathrm{abc}}$ \\
\hline Control & 0.0 & $8.33 \pm 1.155^{\dagger}$ & $8.33 \pm 1.528^{\dagger}$ \\
\hline \multicolumn{4}{|c|}{$\begin{array}{l}\text { Means followed by the same letter (s) in a column are not significantly different } \\
\text { from each other at } p<0.05 \text { according to New Duncan's Multiple Range Test. }\end{array}$} \\
\hline \multicolumn{4}{|c|}{$\begin{array}{c}\text { Keys: } \text { Conc. = Concentration; HTL \& HTB = Hexane leaf and stembark extract of } \\
T . \text { heudelotii, respectively; ETL \& ETB = Ethanol leaf and stembark extract } \\
\text { of } T \text {. heudelotii, respectively; DAT = Day after treatment. }\end{array}$} \\
\hline
\end{tabular}

Effect of Trichilia heudelotii extracts onlarvaemergence of Callosobruchus maculatus at 1 and 30 days after treatment

The larva emergence of Callosobruchus maculatus reared on Trichilia heudelotii non-polar and polar leaf and stem bark extracts at 1 and 30 days after treatment (DAT) is shown in Table 4. There was a significant difference between the treatments and control with all the treatments showing a significant level of reduction in the population of C. maculatus larvae, when compared to the control. At the highest concentration $(1.5 \mathrm{ml})$ and at $1 \mathrm{DAT}$, the non-polar (hex) leaf extract, EtOH leaf and stem bark (polar) extract of T. heudelotii had the least mean number (0.67) of larva emergence of C. maculatus.

While at 30 DAT, only the nonpolar (hex) stem bark extract had the least mean number (0.67) of larva emergence at the highest concentration $(1.5 \mathrm{ml})$ used and was significantly $(p<0.05)$ able to halt the emergence of $C$. maculatus, when compared to the control. The control $(\mathrm{M}=6.00)$ did not affect the emergence of $C$. maculatus larvae throughout the experiment (Table 4). 
Table 4 - Effect of Trichilia heudelotii non-polar and polar leaf and stem bark extracts on larva emergence of Callosobruchus maculatus

\begin{tabular}{|c|c|c|c|}
\hline \multirow{2}{*}{ Treatment } & \multirow{2}{*}{$\begin{array}{c}\text { Conc. } \\
(\mathrm{ml}) / 100 \mathrm{~g} \text { cowpea }\end{array}$} & \multicolumn{2}{|c|}{ Day after treatment (DAT) } \\
\hline & & 1 & 30 \\
\hline \multicolumn{4}{|c|}{ Non-polar extracts } \\
\hline \multirow{3}{*}{ HTL } & 0.5 & $2.00 \pm 1.000^{\mathrm{ab}}$ & $2.67 \pm 1.155^{\mathrm{ab}}$ \\
\hline & 1.0 & $1.33 \pm 1.528^{\mathrm{ab}}$ & $1.67 \pm 0.577^{\mathrm{ab}}$ \\
\hline & 1.5 & $0.67 \pm 1.155^{\mathrm{a}}$ & $1.67 \pm 1.155^{\mathrm{ab}}$ \\
\hline \multirow{3}{*}{ HTB } & 0.5 & $1.33 \pm 1.155^{\mathrm{ab}}$ & $2.00 \pm 1.00^{\mathrm{ab}}$ \\
\hline & 1.0 & $1.33 \pm 0.577^{\mathrm{ab}}$ & $1.33 \pm 0.577^{\text {ab }}$ \\
\hline & 1.5 & $1.00 \pm 1.000^{\mathrm{ab}}$ & $0.67 \pm 0.577^{\mathrm{a}}$ \\
\hline \multicolumn{4}{|c|}{ Polar extracts } \\
\hline \multirow{3}{*}{ ETL } & 0.5 & $1.67 \pm 0.677^{\mathrm{ab}}$ & $2.00 \pm 0.000^{\mathrm{ab}}$ \\
\hline & 1.0 & $1.33 \pm 0.577^{\mathrm{ab}}$ & $1.33 \pm 0.577^{\mathrm{ab}}$ \\
\hline & 1.5 & $0.67 \pm 0.577^{\mathrm{a}}$ & $1.00 \pm 0.000^{\mathrm{ab}}$ \\
\hline \multirow{3}{*}{ ETB } & 0.5 & $1.33 \pm 0.577^{\mathrm{ab}}$ & $2.00 \pm 1.000^{\mathrm{ab}}$ \\
\hline & 1.0 & $1.00 \pm 1.00^{\mathrm{ab}}$ & $1.67 \pm 1.15^{\mathrm{ab}}$ \\
\hline & 1.5 & $0.67 \pm 0.577^{\mathrm{a}}$ & $1.67 \pm 0.577^{\mathrm{ab}}$ \\
\hline Control & 0.0 & $6.00 \pm 1.000^{\mathrm{C}}$ & $6.00 \pm 1.73^{\mathrm{C}}$ \\
\hline
\end{tabular}

Means followed by the same letter (s) in a column are not significantly different from each other at $p<0.05$ according to New Duncan's Multiple Range Test.

Keys: Conc. = Concentration; HTL \& HTB = Hexane leaf and stembark extract of

$T$. heudelotii, respectively; ETL \& ETB = Ethanol leaf and stembark extract of $T$. heudelotii, respectively; DAT = Day after treatment.

Effect of Trichilia heudelotii nonpolar and polar extracts on pupae emergence of Callosobruchus maculatus at 1 and 30 days after treatment

Table 5 shows the effects of the treatment extracts on the emergence of C. maculatus pupae. A significant difference was observed between the treatment extracts and control. At concentration of 1.0 and $1.5 \mathrm{ml}$ and at 1 DAT, the non-polar (hex) stem bark extract and polar (EtOH) leaf extract of $T$. heudelotii had the lowest mean number $(\mathrm{M}=0.67)$ of $C$. maculatus pupae while the lowest mean number $(\mathrm{M}=0.67)$ of $C$. maculatus pupae was also observed for the polar (EtOH) stem bark extract at only $1.0 \mathrm{ml}$ concentration on the same 1 DAT which was significantly $(p<0.05)$ lower, when compared to the control $(\mathrm{M}=4.67)$, which had no reduction in the number of pupae emerging.

The various treatments showed a significant $(p<0.05)$ level of control of $C$. maculatus pupae at 30 DAT (Table 5). However, the non-polar (hex) bark extract and EtOH (polar) leaf extract of $T$. heudelotii gave the lowest mean numbers $(M=0.67)$ of pupae emergence at the highest concentration level $(1.5 \mathrm{ml})$ used. The control showed no reduction in the number of pupae emergence of C. maculatus. 
Table 5 - Effect of T. heudelotii leaf and stem bark (non-polar and polar) extracts on pupae emergence of Callosobruchus maculatus at different concentrations

\begin{tabular}{|c|c|c|c|}
\hline \multirow{2}{*}{ Treatment } & \multirow{2}{*}{$\begin{array}{c}\text { Conc. } \\
(\mathrm{ml}) / 100 \mathrm{~g} \text { cowpea }\end{array}$} & \multicolumn{2}{|c|}{ Day after treatment (DAT) } \\
\hline & & 1 & 30 \\
\hline \multicolumn{4}{|c|}{ Non-polar extracts } \\
\hline \multirow{3}{*}{ HTL } & 0.5 & $1.67 \pm 1.155^{\mathrm{ab}}$ & $2.00 \pm 1.00^{\mathrm{ab}}$ \\
\hline & 1.0 & $1.00 \pm 1.000^{\mathrm{ab}}$ & $1.67 \pm 1.155^{\mathrm{ab}}$ \\
\hline & 1.5 & $1.00 \pm 1.000_{\mathrm{ab}}$ & $1.00 \pm 1.000^{\mathrm{ab}}$ \\
\hline \multirow{3}{*}{ HTB } & 0.5 & $1.33 \pm 0.577^{\mathrm{ab}}$ & $1.67 \pm 0.577^{\mathrm{ab}}$ \\
\hline & 1.0 & $0.67 \pm 0.577^{\mathrm{a}}$ & $1.33 \pm 0.577^{\mathrm{ab}}$ \\
\hline & 1.5 & $0.67 \pm 0.577^{\mathrm{a}}$ & $0.67 \pm 1.155^{\mathrm{a}}$ \\
\hline \multicolumn{4}{|c|}{ Polar extracts } \\
\hline \multirow{3}{*}{ ETL } & 0.5 & $1.33 \pm 0.577^{\mathrm{ab}}$ & $1.67 \pm 0.577^{\mathrm{ab}}$ \\
\hline & 1.0 & $0.67 \pm 0.577^{\mathrm{a}}$ & $1.00 \pm 0.000^{\mathrm{ab}}$ \\
\hline & 1.5 & $0.67 \pm 0.577^{\mathrm{a}}$ & $0.67 \pm 0.577^{\mathrm{a}}$ \\
\hline \multirow{3}{*}{ ETB } & 0.5 & $1.33 \pm 0.577^{\mathrm{ab}}$ & $1.33 \pm 0.577^{\mathrm{ab}}$ \\
\hline & 1.0 & $0.67 \pm 0.577^{\mathrm{a}}$ & $1.67 \pm 0.577^{\mathrm{ab}}$ \\
\hline & 1.5 & $1.00 \pm 1.000^{\mathrm{ab}}$ & $1.00 \pm 0.000^{\mathrm{ab}}$ \\
\hline Control & 0.0 & $4.67 \pm 1.53^{\mathrm{C}}$ & $4.67 \pm 1.155^{c}$ \\
\hline
\end{tabular}

Means followed by the same letter (s) in a column are not significantly different

from each other at $p<0.05$ according to New Duncan's Multiple Range Test.

Keys: Conc. $=$ Concentration; HTL \& HTB $=$ Hexane leaf and stembark extract of

T. heudelotii, respectively; ETL \& ETB = Ethanol leaf and stembark extract of $T$. heudelotii, respectively; DAT = Day after treatment.

Effect of Trichilia heudelotii extracts on the emergence of Callosobruchus maculatus first filial progeny after treatment

Tables 6 and 7 shows the emergence of first filial generation of C. maculatus after treatment with T. heudelotii non-polar (hex) and polar (EtOH) extracts from 28 and 55 DAT. There was a significant difference between the different treatments and the control at 28, 29, 30 and 32 DAT (Table 6). All the various treatments had a significantly low number of progeny emergence whereas the control did not show any reduction in the emergence of C. maculatus progeny. However, at
28 DAT, both the non-polar and polar stem bark extracts (treatments) had the least mean number $(\mathrm{M}=0.00)$ of progeny emergence of $C$. maculatus at a concentration level of $1.5 \mathrm{ml}$, which is significantly lower $(p<0.05)$, when compared to the control, which had the highest mean number $(M=2.67)$ of emergence, as shown in Table 6.

In consideration of the shelf life of the various extracts, Table 7 indicated that the various extracts were significantly $(p<0.05)$ effective from 55 to 59 DAT in the suppression of Callosobruchus maculatus first filial progeny in dose dependent manner, when compared to the control. Further observation revealed that the 
non-polar (hex) and EtOH (polar) stem bark extract of $T$. heudelotii gave the least numbers of F1 progeny emergence at the highest concentration $(1.5 \mathrm{ml})$ at 55 (0.33), $57(0.33)$ and
59 (0.33) DAT, respectively, and were the best extracts in restricting the emergence of new generation of Callosobruchus maculatus from 55 DAT as shown in Table 7.

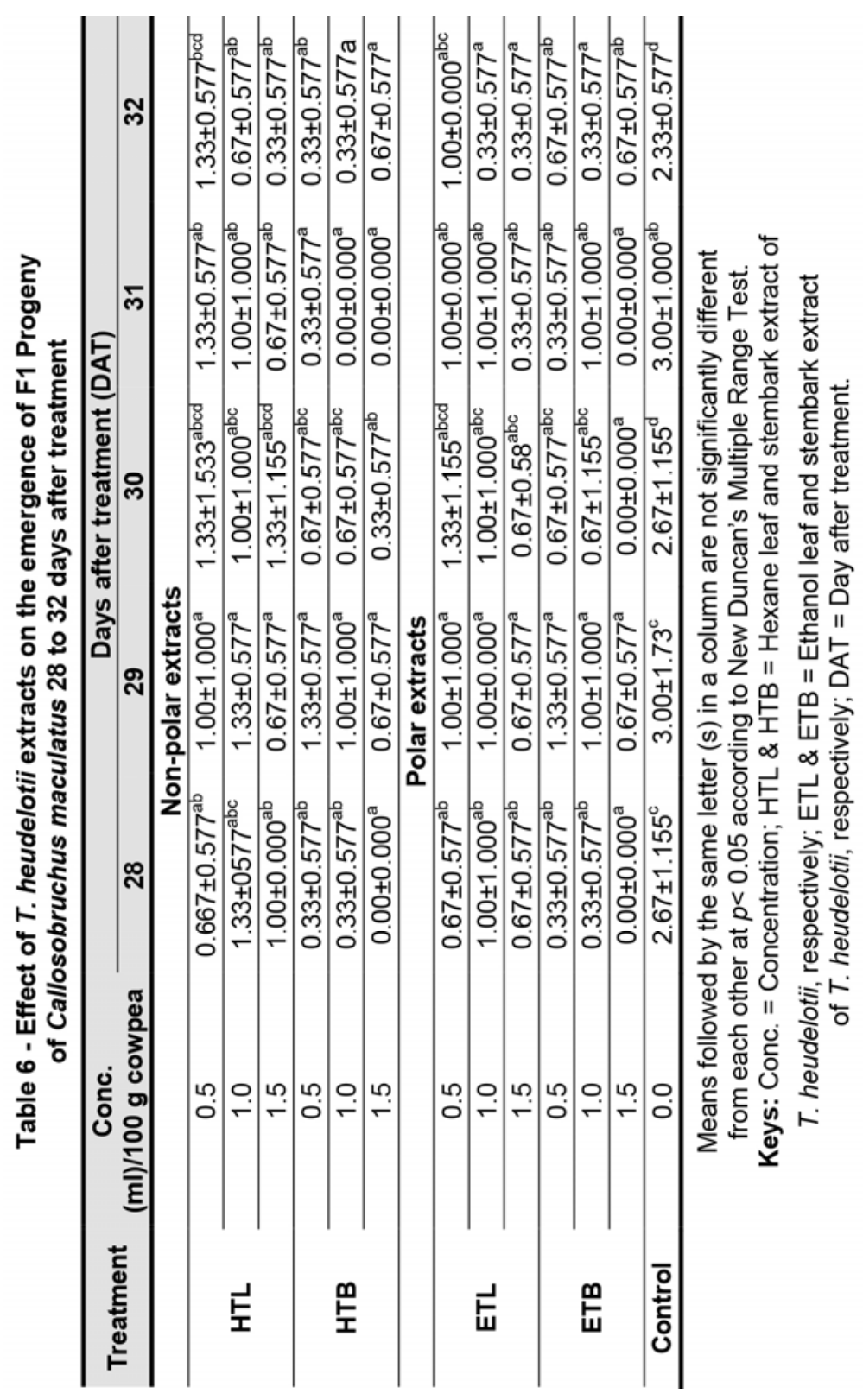




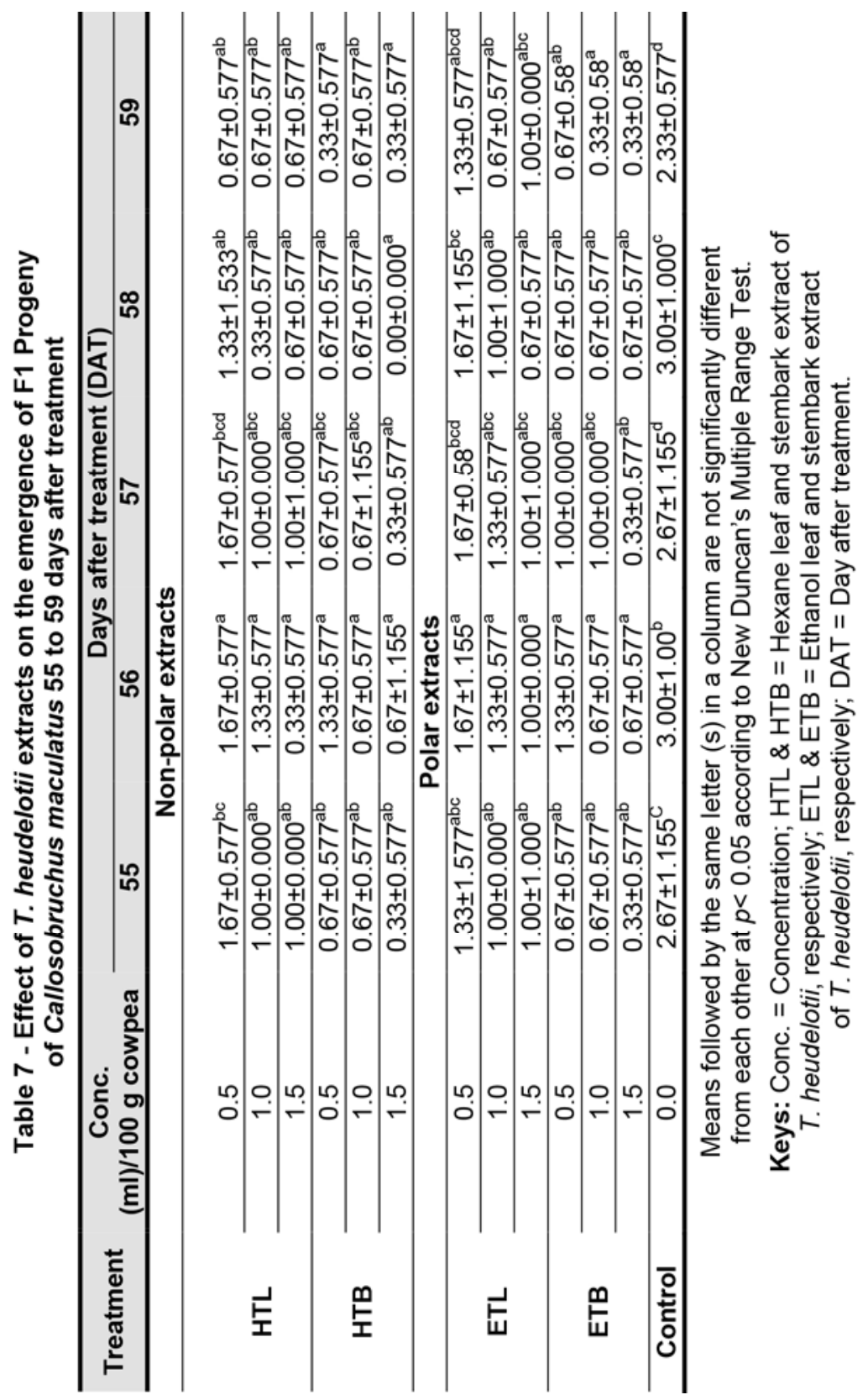


Qualitative phytochemical analysis of $T$. heudelotii leaf and bark

Phytochemical analysis of both the non-polar (hex) and polar (EtOH) leaf and stem bark extracts of
T. heudelotii is shown in Table 8. The result revealed the presence of flavonoids, terpenoids, alkaloids, saponins in both the non-polar and polar extracts of the plant.

Table 8 - Qualitative phytochemical analysis of Trichilia heudelotii leaf and stem bark extracts

\begin{tabular}{ccccc}
\hline Phytochemicals & \multicolumn{2}{c}{ Leaf extract } & \multicolumn{2}{c}{ Stembark extract } \\
\hline & HTL & ETL & HTB & ETB \\
\hline Flavonoids & - & + & + & + \\
\hline Terpenoids & + & + & + & + \\
\hline Saponins & + & + & + & + \\
\hline Alkaloids & + & + & + & + \\
\hline Tannins & - & - & - & + \\
\hline Anthraquinones & - & - & - & - \\
\hline Steroids & + & - & + & - \\
\hline Phenolic compounds & - & + & - & + \\
\hline Anthocyanins & - & - & - & - \\
\hline
\end{tabular}

Keys: + = present; - = absent; HTL \& ETL = Hexane and ethanol leaf extract of Trichilia heudelotii, respectively; HTB \& ETB = Hexane and ethanol stembark extract Trichilia heudelotii, respectively.

\section{DISCUSSIONS}

The genus Trichilia has been reported to be a good source of different classes of compounds with insecticidal potentials in the control of insect pests (Sengottayan, 2013; Curcino-Vieira et al., 2014; García-Gómez et al., 2019). The use of different polarity of organic solvent extracts of both leaf and stem bark of $T$. heudelotii gave strong insecticidal activities against the various life stages of $C$. maculatus. To the best of our knowledge, this is the first report of the insecticidal potential of extracts from leaf and stem bark of T. heudelotii. In the ability to cause adult mortality, the polar EtOH extract of $T$. heudelotii stem bark was observed to be the most effective at increasing concentration and therefore served as the best extract in the suppression of C. maculatus adults. This findings was in accordance with the reports of some scientists stating the use polar extracts of various plant parts of different Trichilia species (from genus Trichilia) with antifeedant effects on Spodoptera litura and the last instar of Spodoptera exigua (López-Oleguín, 1998; Wheeler and Isman, 2001). Similarly, in 2019, García-Gómez and co-workers reported the reduction in the mean survival time of the larvae of Copitarsia decolora using methanol (polar) stem bark extract of another Trichilia species (Trichilia hirta) from the same genus. 
Furthermore, the presence of these classes of compounds; saponins, terpenoids, alkaloids, steroids and tanins lying more in the stem bark EtOH polar extract of the plant could probably have caused induction of the quick mortality of $C$. maculatus used in this study as a result of the polar extract incapacitating more adults of the insect (López-Oleguín, 1998; Wheeler and Isman, 2001). The adult mortality effect could also be attributed to the different phytochemicals extracted from the leaf and stem bark of theplant (Sengottayan, 2013; Curcino-Vieira et al., 2014; García-Gómez et al., 2019).

In addition, the shelf life of T. heudelotii extracts against C. maculatus adults investigated in this study revealed that the organic extracts (both non-polar and polar) used was effective at an extended time of 30 days when applied and thus could provide long term protection on stored cowpea against the insect pest and as such could possibly serve as an excellent alternative to synthetic insecticides. At the highest concentration $(1.5 \mathrm{ml})$ used, all the extracts were significantly able to suppress the oviposition rate of C. maculatus, however the EtOH (polar) extract of stem bark of T. heudelotii gave the least oviposition also suggesting the use of the polar extract as an alternative crop protectant. Previous reports has shown the use of various polar organic extracts (aqueous, methanol, acetone, ethyl acetate) of Trichilia Americana, Trichilia hirta and
Trichilia havanensis had reduced fecundity of Copitarsia decolora at least by one-third and fertility by almost $50 \%$ at $1,500 \mathrm{ppm}$ (GarcíaGómez et al., 2019). Thus, the results in this study was not far-fetch.

All the plant treatments (extracts) at the larvae and pupae stage of $C$. maculatus showed significant levels of restriction of the larvae emergence and pupation of the insect pest. However, the non-polar (hex) leaf extract, both polar (EtOH) leaf and stem bark extracts of T. heudelotii had the least mean number of $C$. maculatus larvae emergence, while on the pupae emergence, the polar (EtOH) leaf, both the non-polar (hex) and polar (EtOH) stem bark extracts of the plant gave the lowest emergence of pupae of the insect pest all at an increased concentration rate of $1.5 \mathrm{ml}$.

At 30 DAT, the shelf life of the organic extracts indicated that the non-polar (hex) stem bark of $T$. heudelotii at $1.5 \mathrm{ml}$ had the least mean larvae and pupae emergence as well as the polar (EtOH) leaf extract giving fewer pupae emergence, though, all the treatment extracts were sufficiently effective in restricting the larvae and pupae emergence of the insect pest at an extended period of 30 days, compared to the control which did not show significant reduction in the emergence of C. maculatus. Therefore, these effects on larval and pupae emergence as a result of the use of the extracts of T. heudelotii may be due to hormone alterations interfering with the process 
(Mordue and Blackwell, 1993). Our findings were in accordance with those reported in literature where the polar extract (methanol-MeOH) of Trichilia hirta stem bark significantly reduced the mean survival time of the larvae of Copitarsia decolora (GarcíaGómez et al., 2019). Similarly, another specie from the genus Trichilia (Trichilia sylvatica) was previously reported to have decrease in fecundity and fertility by about 87 to $100 \%$ of Spodoptera frugiperda when its larvae were fed with polar $(\mathrm{MeOH})$ extract (Freitas et al., 2014).

The treatment (extracts) of $T$. heudelotii used in this study also showed a significant reduction in the emergence of $C$. maculatus filial progeny. Close observations showed that both the non-polar (hex) and polar (EtOH) stem bark extracts of the plant at the highest concentration rate had the least number of $C$. maculatus first filial progeny emergence and performed better in its ability to suppress the emergence of the new generation of the insect pest. Aba-Toumnou et al. (2016) reported the use of both non-polar (hex) and polar (ethyl acetate- EtOAc) extracts of Trichilia gilgiana being effective against different storage pests; $S$. zeamais, $T$. castaneum and $R$. dominica. The insecticidal activity of $T$. gilgiana against $S$. zeamais and $T$. castaneum were also found in literature (Aba-Toumnou et al., 2012b). Previous reports cited in this study further corroborates our findings, suggesting the use of different polarity of organic solvents extracts of Trichilia heudelotii as a natural alternative remedy for crop protectants against insect pests.

\section{CONCLUSION}

Non-polar (hex) and polar (EtOH) extracts of Trichilia heudelotii were effective in controlling the various life stages of bruchid population in stored cowpea. Strong insecticidal activities against $C$. maculatus with a high rate of mortality were reported within 96 hours using both non-polar and polar extracts of Trichilia heudelotii leaf and stem bark at the highest concentration $(1.5 \mathrm{ml})$. In addition, the extracts were able to protect the cowpea against $C$. maculatus at an extended period of 30 days suggesting the extracts to possess a long term insecticidal effect against insects' pest infesting cowpea. The potential of T. heudelotii extracts as a plant derived insecticides in the control of C. maculatus could further be studied to investigate it's usage as an eco-friendly biopesticides alternative to the use of conventional synthetic pesticides. Further research is suggested to possibly isolate the actual compound(s) responsible for the insecticidal activities and further testing carried out. Thus, $T$. heudelotii could possibly serve as a sustainable means of pest control where the plant is readily available in high quantity.

\section{REFERENCES}

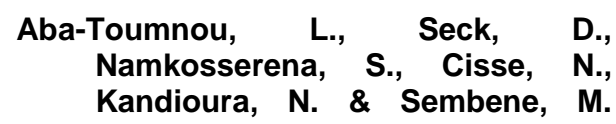


(2012). Utilisation des plantes indigènes à effet insecticide pour la protection des denrées stockées contre des insectes ravageurs à Boukoko (Centrafrique). Int.J.Biol. Chem.Sci., 6(3): 1040-1050, DOI: 10.4314/ijbcs.v6i3.11

Aba-Toumnou, L., Wango, S.P., KoshKomba, E., Namkosséréna, S., Bolevane-Ouatinam et al. (2016). The effective insecticidal activity of the two extracts ethyl acetate and hexan of Trichilia gilgiana against Sitophilus zea maïs. Int.J.Biol., 8(2): 23-31, DOI: 10.5539/ijb.v8n2p23

Addor, R.W. (1995). Insecticides. In: Godfrey, C.R.A. (Ed.), Agrochemicals from natural products (pp. 1-62). Marcel Dekker, Inc.

Ali, S.M., Mahgoub, S.M., Hamed, M.S. \& Gharib, M.S.A (2004). Infestation potential of Callosobruchus chinensis and Callosobruchus maculatus on certain broad bean seed varieties. Egypt.J.Agric.Res., $\quad 82(3)$ : $1127-$ 1135.

Ayo, R.G., Audu, O.T., Amupitan, J.O. \& Uwaiya, E. (2013). Phytochemical screening and antimicrobial activity of three plants used in traditional medicine in Northern Nigeria. J.Med. Plants Res., 7(5): 191-197, DOI: 10. 5897/JMPR12.1030

Bankole, A.E., Adekunle, A.A., Sowemimo, A.A., Umebese, C.E., Abiodun, O. \& Gbotosho, G.O. (2016). Phytochemical screening and in vivo antimalarial activity of extracts from three medicinal plants used in malaria treatment in Nigeria. Parasitol.Res. 115: 299-305, DOI: 10.1007/s00436-015-4747-x

Beck, C.W. \& Blumer, L.S. (2014). A handbook on bean beetles, C. maculatus (p. 17). The National Science Foundation.

Curcino-Vieira, I.J., Silva-Terra, W., Dos Santos, G.M. \& Braz-Filho, R. (2014). Secondary metabolites of the genus Trichilia: contribution to the chemistry of Meliaceae family. Am.J.
Analyt.Chem., 5(2): 91-121, DOI: 10.4236/ajac. 2014.52014

Egho, E.O. (2011). Management of major field pests and yield of cowpea (Vigna unguiculata (L.) Walp) under calendar and monitored application of synthetic chemicals in Asaba, Southern Nigeria. Am.J.Sci.Ind.Res., 2(4): 592-602, DOI: doi:10.5251/aj sir.2011.2.4.592.602

Fox, C.W. \& Reed, D.H. (2011). Inbreeding depression increases with environmental stress: an experimental study and meta-analysis. Evolution, 65(1): 246-258, DOI: 10.1111/j.15585646.2010.01108.x

Freitas, A.F., Formagio, A.S.N., Pereira, F.F., Lucchetta, J.T. \& Vieira, M.D.C (2014). Effect of extracts of Trichilia silvatica C. DC. on development and reproduction parameters of Spodoptera frugiperda (J.E. Smith) (Lepidoptera: Noctuidae). Afr.J.Biotechol., 13(20): 2014-2049, DOI: 10.5897/AJB2014.13768

García-Gómez, A., Figueroa-Brito, R., García-Serrano, L A. \& JiménezPérez, A. (2019). Trichilia (Meliaceae) plants: an important source of biomolecules with insecticidal properties. Fla. Entomol., 101(3): 470-479, DOI: 10.1653/024. 101.0305

Harborne, J.B. (1973). Phytochemical methods: a guide to modern technique of plant analysis. Chapman and Hall Ltd.

Isman, M.B. (2001). Pesticides based on plant essential oils for management of plant pests and diseases. International symposium on development of natural pesticides from forest resources. Korea Forest Research Institute, pp. 1-9.

Kéïta, S.M., Vincent, C., Schmit, J.B., Ramaswamy, S. \& Bélanger, A. (2000). Effects of various essential oils on Callosobruchus maculatus (F.) (Coleoptera: Bruchidae). J. Stored Prod.Res., 36(4): 355-364, DOI: 10.1016/S0022-474X(99)0005 5-7 


\section{NOVEL APPLICATION OF TRICHILIA HEUDELOTII ON THE CONTROL OF COWPEA BEETLE}

Kergoat, G.J., Silvain, J.F, Delobel, A., Tuda, M. \& Anton, K.W. (2007). Defining the limits of taxonomic conservatism in host-plant use for phytophagous insects: Molecular systematics and evolution of hostplant associations in the seed-beetle genus Bruchus linnaeus (Coleoptera: Chrysomelidae: Bruchinae). Mol. Phylogen.Evol., 43(1): 251-269, DOI: 10.1016/j.ympev.2006.11.026

Lajide, L., Adedire, C.O., Muse, W.A. \& Agele, S.O. (2003). Insecticidal activities of some Nigeria plant extract against cowpea weevil (Callosobruchus maculatus) Entomological Society of Nigeria occasional publications, 31: 235-247.

Langyintuo, A.S., Lowenberg-DeBoer, J., Faye, M., Lamber, D., Ibro, G. et al. (2003). Cowpea supply and demand in West and Central Africa. Field Crops Res., 82(2-3): 215-231, DOI: $\quad 10.1016 / S 0378-4290(03) 0003$ $9-X$

López-Olguín, J.F. (1998). Actividad y modo de acción de productos de Trichilia havanensis Jacq. y Scutellaria alpina subsp. javalambrensis (Pau), sobre Leptinotarsa decemlineata (Say) y Spodoptera exigua (Hübner). Tesis de Doctorado. Escuela Técnica Superior de Ingenieros Agrónomos. Universidad Politécnica de Madrid. Madrid, España.

Mordue, A.J. \& Blackwell, A. (1993). Azadirachtin: an update. J.Insect Physiol., 39(11): 903-924, DOI: 10. 1016/0022-1910(93)90001-8

Ousman, A., Ngassoum, M.B., EssiaNgang, J.J., Ngamo, L S.T. \& Ndjouenke, R. (2007). Insecticidal activity of spicy plant oils against Sitophilus zeamais in stored maize in Cameroon. Agric.J., 2(2): 192-196, DOI: aj.2007.192.196

Ramírez, M.C., Toscano, R.A., Arnason, J., Omar, S., Cerda-García-Rojas, C.M. \& Mata, R. (2000). Structure, conformation and absolute configuration of new antifeedant dolabellanes from Trichilia trifolia. Tetrahedron, 56: 5085-5091.

Rodrigues, V.F., Carmo, H.M., BrazFilho, R., Mathias, L. \& Vieira, I.J.C. (2010). Two new terpenoids from Trichilia quadrijuga (Meliaceae). Nat.Prod.Commun., 5(2): 179-184, DOI: $10.1177 / 1934578 \times 1000500202$

Savithramma, N., Rao, M.L. \& Suhrulatha, D. (2011). Screening of medicinal plants for secondary metabolites. Middle-East J.Sci.Res., 8(3): 579-584.

Sengottayan, S.N. (2013). Physiological and biochemical effect of neem and other Meliaceae plants secondary metabolites against Lepidopteran insects. Front.Physiol., 4: 359, DOI: 10.3389/fphys. 2013.00359

Singh, B.B. (2002). Recent genetic studies in cowpea. In: Fatokun, C.A., Tarawali, S.A., Singh, B.B., Kormawa, P.M. \& Tamo, M. (Eds.), Challenges and Opportunities for Enhancing Sustainable Cowpea Production (pp. 3-13). Intl.Inst. Tropical Agric, Ibadan, Nigeria.

Singh, B.B (2005). Cowpea (Vigna unguiculata (L.) Walp. In: Singh R.J. \& Jauhar, P.P. (Eds.), Genetic Resources, Chromosome Engineering and Crop Improvement (pp. 117-162). CRC Press, Boca Raton, FL, USA.

Sofowora, L.A. (1993). Medicinal plants and traditional medicine in Africa spectrum. Spectrum Books Ltd., Ibadan, 191-289.

Swella, G.B. \& Mushobozy, D.M.K. (2007). Evaluation of the efficacy of protectants against cowpea bruchids (Callosobruchus maculatus (F.)) on cowpea seeds (Vigna unguiculata (L.) Walp.). Plant Protect.Sci., 43(2): 68-72, DOI: 10.17221/2256-PPS

Talukder, F.A. \& Howse, P.E. (1995). Laboratory evaluation of toxic and repellent properties of the pitharaj tree, Aphanamixis polstachya Wall \& Parker, against Sitophilus oryzae (L.). Int.J. Pest Manag., 40(3): 274279. 
Timko, M.P., Ehlers, J.D. \& Roberts, P.A (2007a). Cowpea: In Kole C. (Ed.), Genome Mapping and Molecular Breeding in Plants: Pulses, Sugar and Tuber Crops (pp. 49-67), Springer Verlag, Berlin Heidelberg.

Trease, G.E. \& Evans, W.C. (1989). Pharmacognosy. 11th Edition, Bailliere Tindall, London, 45-50.

Umar, A. \& Turaki, J.M. (2014). Comparative studies on the biology of Callosobruchus maculatus (F.) on soya beans and bambara groundnut. J.Entomol.Zool.Stud., 2(4): 58-61.

Umeozor, O.C. (2005). Effect of the infection of Callosobruchus maculatus (Fab.) on the weight loss of stored cowpea (Vigna unguiculata (L.) Walp). JASEM, 9(1): 169-172.

Vieira, I.J.C., Azevedo, O.A., Souza, J.J., Braz-Filho, R., Gonçalves, M.S. \& Araújo, M.F. (2013). Hirtinone, a novel cycloartane-type triterpene and other compounds from Trichilia hirta L. (Meliaceae). Molecules, 18(3): 2589-2597, DOI: 10.3390/molecules 18032589

Vieira, I.J.C., Terra, W.S., Gonçalves, M.S. \& Braz-Filho, R. (2014). Secondary metabolites of the genus Trichilia: Contribution to the Chemistry of Meliaceae family. Am.J.Anal.Chem., 5: 91-121.

Wheeler, D. \& Isman, M. (2001). Antifeedant and toxic activity of Trichilia Americana extract against the larvae of Spodoptera litura. Entomol.Exp.Appl., 98(1): 9-16, DOI: 10.1046/j.1570-7458.2001.00751.x

Xie, Y.S., Isman, M.B., Cunning, P., Mackinnon, S., Arnason, J.T. et al. (1994). Biological activity of extracts of Trichilia species and the limonoids hirtin against lepidopteran larvae. Biochem.Syst.Ecol., 22(2): 129-136. 